Pesq. Vet. Bras. 29(4):339-344, abril 2009

\title{
Imunofenotipagem e avaliação quantitativa de linfócitos circulantes de bovinos da raça Curraleiro'
}

\author{
Júlia M. Moraes ${ }^{2 *}$, Luiz A.B. Brito ${ }^{3}$, Veridiana M.B.D. de Moura ${ }^{3}$, Carolina S. \\ Ribeiro ${ }^{4}$, Victor Y. Guimarães ${ }^{4}$, Diogo F. Andrade ${ }^{4}$, Joyce R. Lobo² e Maria \\ Clorinda S. Fioravanti ${ }^{3}$
}

\begin{abstract}
Moraes J.M., Brito L.A.B., Moura V.M.B.D., Ribeiro C.S., Guimarães V.Y., Andrade D.F., Lobo J.R. \& Fioravanti M.C.S. 2009. [Immunophenotyping and quantitative evaluation of circulating lymphocytes of cattle of the Curraleiro breed.] Imunofenotipagem e avaliação quantitativa de linfócitos circulantes de bovinos da raça Curraleiro. Pesquisa Veterinária Brasileira 29(4):339-344. Escola de Veterinária, Universidade Federal de Goiás, Campus Samambaia, Cx. Postal 131, Goiânia, GO 74001970, Brazil. E-mail: mmjulia_vet@yahoo.com.br

The aim of this study was to establish an immunological profile by marking and quantification of $T$ and $B$ lymphocytes in Curraleiro breed by immunocytochemistry. A total of 116 cattle was used, males and females of different ages, from two farms situated in the Goiás State, Brazil. The animals were allotted into groups according to age, sex and origin. Blood samples were collected and processed in accordance with immunocytochemistry standard technique using lymphoid markers species-specific, as anti-CD3 (MM1 A - BoCD3) and anti-LB (LCTB16A-clone B-B14), for T and B lymphocyte counting, respectively. The data were submitted to descriptive statistics, and to Kruskall Wallis and Mann-Whitney tests. The results showed decreased levels of leukocytes, lymphocytes, T lymphocytes and $B$ lymphocytes along the age advance. Absolute values of leukocytes, lymphocytes and T lymphocytes were higher in males than females. None of the evaluated parameters were affected by differences of the management carried out at the two farms.
\end{abstract}

INDEX TERMS: Immunocytochemistry, CD3, T lymphocytes, B lymphocytes, immunological profile.

RESUMO.- Este estudo teve por objetivo traçar o perfil imunológico, pela marcação imunocitoquímica e quantificação de linfócitos $\mathrm{T}$ e $\mathrm{B}$, de bovinos da raça Curraleiro. Para tal, foram utilizados 116 animais entre machos e fêmeas, de diferentes faixas etárias, provenientes de duas propriedades de criação de gado Curraleiro do Estado de Goiás, sendo alocados em grupos conforme a faixa etária, sexo e origem. As amostras de sangue foram colhidas e

\footnotetext{
${ }^{1}$ Recebido em 19 de dezembro de 2008.

Aceito para publicação em 27 de fevereiro de 2009.

2 Pós-graduanda em Ciência Animal, Escola de Veterinária, Universidade Federal de Goiás (UFG), Campus Samambaia (Campus II), Cx. Postal 131, Goiânia, GO 74001-970, Brasil. *Autor para correspondência: mmjulia_vet@yahoo.com.br

3 Setor de Patologia Animal, Escola de Veterinária, UFG, Campus Samambaia, Cx. Postal 131, Goiânia, GO 74001-970.

${ }^{4}$ Graduando em Medicina Veterinária, Escola de Veterinária, UFG, Campus Samambaia, Cx. Postal 131, Goiânia, GO 74001-970.
}

processadas para a realização da técnica de imunocitoquímica, sendo utilizados os marcadores linfóides espécie-específicos, anti-CD3 (MM1A-BoCD3) e anti-LB (LCTB16A-clone B-B14), para a quantificação de linfócitos $T$ e $B$, respectivamente. Inicialmente os dados foram submetidos à estatística descritiva e, posteriormente, aos testes de Kruskall Wallis e Mann-Whitney. Verificou-se que, com o avançar da idade, os níveis de leucócitos, linfócitos, linfócitos T e B diminuíram. Os valores absolutos de leucócitos, linfócitos totais e linfócitos $T$ foram maiores nos machos. Nenhum dos parâmetros avaliados sofreu influência em relação à qualidade do manejo nas propriedades.

TERMOS DE INDEXAÇÃO: Imunocitoquímica, CD3, linfócitos $T$, linfócitos $B$, perfil imunológico.

\section{INTRODUÇÃO}

O gado que deu origem ao bovino Curraleiro (Bos taurus ibericus), também conhecido como Pé-duro, foi trazido 
da Península lbérica para o Brasil pelos portugueses na época da colonização (Mariante \& Egito 2002). Atualmente, plantéis desses animais são encontrados no Maranhão, Piauí, Goiás e Tocantins, sendo que os criadores ressaltam a rusticidade, o baixo custo de produção e a baixa exigência nutricional como qualidades indiscutíveis da raça (Juliano 2006). De acordo com Carvalho \& Amorim (1989), a raça formou-se em regime de criação super extensiva, resultando em animais extremamente rústicos, que constituem excelente recurso genético para a pecuária brasileira.

A resistência a doenças é um atributo particularmente importante nos sistemas de produção pecuária e a sanidade pode ser fator limitante na sua sustentabilidade (Gibson 2002). Embora as raças naturalizadas brasileiras sejam menos produtivas que as comerciais, despertando pouco interesse por parte dos criadores, são perfeitamente adaptadas às nossas condições, bem como resistentes a doenças e parasitas, podendo trazer grandes contribuições aos programas de melhoramento genético (Rangel et al. 2004).

A possibilidade de aumentar a resistência genética a doenças em um rebanho é viável aplicando-se técnicas simples como a inclusão de raças nativas ou naturalizadas nos programas de melhoramento genético, ou ainda, utilizando marcadores moleculares na seleção de reprodutores (Gibson 2002, Gibson \& Bishop 2005). Além disso, os cruzamentos industriais seriam uma alternativa de utilização do gado Curraleiro, com o intuito de obter animais mais resistentes e adaptados (Barini 2007).

A extinção de raças naturalizadas brasileiras representaria a indisponibilidade de informações contidas na estrutura genética desenvolvida ao longo de séculos de seleção natural, conferindo ao Curraleiro características de boa adaptação ao meio e maior resistência a doenças e parasitas (Mariante \& Cavalcante 2000).

A resistência do Curraleiro às enfermidades que comumente afetam rebanhos bovinos é popularmente conhecida e divulgada, porém pouco se conhece sobre o sistema imunológico desses animais (Juliano 2006). Desta forma, este trabalho teve como objetivo traçar o perfil imunológico de bovinos da raça Curraleiro, de ambos os sexos e diferentes idades e estabelecer comparação entre propriedades submetidas a manejos nutricionais e sanitários distintos, pela imunofenotipagem e quantificação de linfócitos circulantes.

\section{MATERIAL E MÉTODOS}

Avaliaram-se 116 bovinos da raça Curraleiro (Bos taurus ibericus), entre machos e fêmeas, de diferentes faixas etárias, hígidos e mantidos em sistema de criação extensiva. Foram colhidas amostras de sangue no período de agosto a dezembro de 2007, de duas propriedades, uma no município de Planaltina, DF (Propriedade A) e outra no município de Caiçara, GO (Propriedade B). As propriedades foram selecionadas junto à Associação Brasileira dos Criadores do Gado Curraleiro (ABCC), com base na pureza zootécnica dos animais.
Os animais foram distribuídos em oito grupos conforme o sexo, faixa etária e propriedade de origem, sendo G1: fêmeas, 1-3 anos, Propriedade A $(n=10)$; G2: fêmeas, $>3$ anos, Propriedade A $(n=15)$; G3: fêmeas, d"1 ano, Propriedade B ( $n=22)$; G4: machos, d"1 ano, Propriedade B ( $n=16)$; G5: fêmeas, 1-3 anos, Propriedade B $(n=9)$; G6: fêmeas, 3-9 anos, Propriedade B ( $n=26)$; G7: fêmeas, e"10 anos, Propriedade B $(n=14)$; e G8: machos, $>1$ ano, Propriedade B $(n=4)$.

Em decorrência dos manejos alimentar e sanitário diferentes nas duas propriedades, os animais apresentavam condições corporal e sanitária distintas. Na propriedade A, o sistema de criação era extensivo, sendo a área de pastagem dividida em piquetes com capim Braquiária, Colonião e Jaraguá, com suplementação durante todo o ano apenas com sal mineral. 0 controle de ectoparasitas era realizado periodicamente. Os animais apresentavam-se em boas condições clínica e corpórea, com escores variando entre três e quatro, de acordo com o descrito por Allen (1992). Na propriedade B, o sistema de criação também era extensivo, contudo a pastagem composta apenas de capim Braquiária. Os animais não recebiam suplementação e apresentavam escores entre um e três. O controle de ectoparasitas não era realizado, observando-se infestação moderada de carrapatos e mosca do chifre.

Para a realização dos exames hematológicos foram obtidos $4 \mathrm{ml}$ de sangue, por venopunção da jugular, em tubo de coleta a vácuo de $13 \times 75 \mathrm{~mm}$, com anticoagulante EDTA (ácido etilediaminotetracético sal dissódico) a $10 \%$ e agulhas descartáveis de $25 \times 0,8 \mathrm{~mm}$. As amostras destinadas a hematimetria permaneceram sob refrigeração até o momento da realização das análises, sempre num período inferior a 24 horas da colheita.

Para a contagem diferencial de leucócitos foram realizados dois esfregaços sangüíneos com o sangue in natura. Após a secagem, os esfregaços foram imediatamente fixados em metanol, por cinco minutos e acondicionados adequadamente, para posterior coloração pelo método de Rosenfeld, segundo Birgel (1982), sendo as lâminas avaliadas conforme critérios descritos por Jain (1993).

Os hemogramas foram processados em aparelho automatizado (ABX Micros ABC Vet - Horiba ABX Diagnostics, Montpellier, França), utilizando-se cartão de leitura próprio para a espécie. Nesses foram determinados os valores de eritrograma e leucograma, considerando os referenciais descritos por Paula Neto (2004). O fibrinogênio plasmático foi dosado com o objetivo de monitorar a higidez dos animais, sendo utilizada a técnica do microhematócrito e as orientações de Coles (1986).

Os espécimes clínicos destinados à imunocitoquímica foram preparados adaptando-se a técnica universal de contagem total

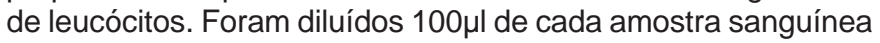
em 2000 $\mu l$ de Líquido de Türk e centrifugados por cinco minutos a 3000rpm, sendo o sedimento homogeneizado e aspirado em pipetas hematimétricas.

O conteúdo aspirado foi então distribuído em lâminas histológicas silanizadas, em uma área de formato ovalado, de aproximadamente $2 \mathrm{~cm}$ de diâmetro e previamente delimitada com caneta hidrofóbica. Seqüencialmente realizou-se a homogeneização do sedimento nas lâminas, aguardando-se a secagem.

Para a técnica de imunocitoquímica foram empregados os anticorpos monoclonais anti-CD3 (MM1A - BoCD3, anti-mouse, VMRD Inc., Pullman, USA) e anti-LB (LCTB16A - B-B14, antimouse, VMRD Inc., Pullman, USA), espécie-específicos para bovinos e o método streptoavidina-biotina-peroxidase (Hsu et 
al. 1981). As lâminas foram submetidas a recuperação antigênica (solução tampão citrato pH 6,0, por 30 minutos, à $95^{\circ} \mathrm{C}$ e em banho-maria), o bloqueio da peroxidase endógena $\left(\mathrm{H}_{2} \mathrm{O}_{2}\right.$ a $5 \%$, em dois banhos de 10 minutos) e o bloqueio de marcação inespecífica (Soro Albumina Bovina a 3\% por uma hora e solução de leite desnatado por 30 minutos, ambas em câmara úmida à temperatura ambiente). Entre as etapas as lâminas foram lavadas em solução tampão de TRIS pH 7,4.

Em seguida, as lâminas foram incubadas com anticorpo primário diluído em solução diluidora de anticorpos (Antibody Diluent, Dako ${ }^{\circledR}$ S3022, Carpinteria, CA, USA), em câmara úmida, a $4^{\circ} \mathrm{C}$, durante 18 horas (overnight), nas diluições 1:100 para 0 anticorpo anti-CD3 e 1:50 para o anticorpo anti-LB. Para a amplificação e revelação da reação empregaram-se o complexo streptoavidina-biotina-peroxidase (LSAB, Dako ${ }^{\circledR}$ K0690, Carpinteria, CA, USA) e solução de diaminobenzidina-peroxidase (DAB-peroxidase, Dako ${ }^{\circledR}$ K3468, Carpinteria, CA, USA), conforme recomendação do fabricante. A solução de TRIS foi utilizada entre as etapas para a lavagem das lâminas. O material foi então contracorado com hematoxilina de Mayer e as lâminas montadas com resina sintética e lamínulas histológicas.

Para a avaliação quantitativa linfocitária foi adaptado o procedimento de contagem diferencial de leucócitos descrito por Kimura et al. (1999). De um total de 100 linfócitos marcados e não marcados, foi considerado apenas o efetivo de células marcadas, determinando-se os percentuais de linfócitos T e B. Estes foram transformados em valores absolutos, em relação ao número de linfócitos absolutos totais obtidos na contagem diferencial de leucócitos, conforme preconizado por Ayoub \& Yang (1996).

Os grupos para a análise estatística foram compostos da seguinte maneira: (1) Avaliação do efeito idade: G1+G5 x G2+G6 x G3 x G7; (2) Avaliação do efeito sexo: G3+G5 x G4+G8; e (3) Avaliação do efeito propriedade: $\mathrm{G} 1+\mathrm{G} 2$ x G5+G6. Inicialmente os dados foram submetidos à estatística descritiva e, posteriormente, foi utilizado o teste de Kruskal-Wallis para a comparação das médias entre as diferentes faixas etárias, e o teste de Mann-Whitney, para comparação entre os diferentes sexos e propriedades, ambos ao nível de significância $p<0,05$ (Sampaio 2007).

\section{RESULTADOS}

Os percentuais de células marcadas para os anticorpos anti-CD3 e anti-LB, em uma população de 116 bovinos da raça Curraleiro, foram 64 e 32, respectivamente. As reações imunocitoquímicas positivas os anticorpos anti-CD3 e anti-LB caracterizaram-se pela visualização de um deli-

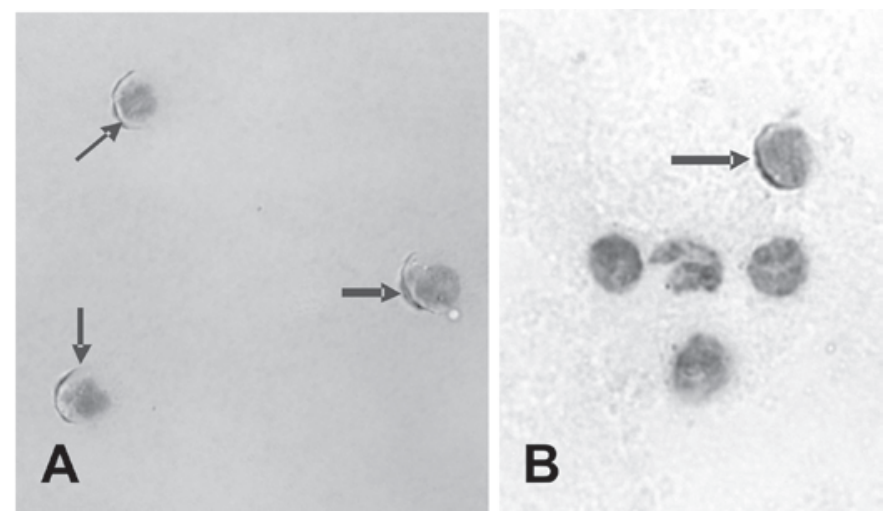

Fig.1. Fotomicrografia de amostras confeccionadas com sangue de bovinos diluídos em Líquido de Türk. (A) Linfócito marcado pelo anticorpo monoclonal MM1A, anti-CD3 (setas vermelhas). (B) Linfócito marcado pelo anticorpo monoclonal LCTB16A, anti-LB (seta vermelha). ICQ, LSAB, DAB, contra-coloração Hematoxilina de Mayer, obj.100x.

Quadro 1. Valores médios e desvio padrão dos percentuais de linfócitos $T$ e $B$, em sangue periférico, submetido à técnica de imunocitoquímica, de fêmeas bovinas da raça Curraleiro, conforme a faixa etária

\begin{tabular}{ccccc}
\hline Grupos & $\mathrm{G} 3$ & $\mathrm{G} 1+\mathrm{G} 5$ & $\mathrm{G} 2+\mathrm{G} 6$ & $\mathrm{G7}$ \\
\cline { 2 - 5 } & $\begin{array}{c}\leq 1 \text { ano } \\
(\mathrm{n}=22)\end{array}$ & $\begin{array}{c}1-3 \text { anos } \\
(\mathrm{n}=19)\end{array}$ & $\begin{array}{c}3-9 \text { anos } \\
(\mathrm{n}=41)\end{array}$ & $\begin{array}{c}\geq 10 \text { anos } \\
(\mathrm{n}=14)\end{array}$ \\
\hline Linfócitos T (\%) & $67^{\mathrm{a}} \pm 6$ & $62^{\mathrm{a}} \pm 6$ & $64^{\mathrm{a}} \pm 6$ & $64^{\mathrm{a}} \pm 8$ \\
Linfócitos B (\%) & $34^{\mathrm{a}} \pm 5$ & $27^{\mathrm{b}} \pm 6$ & $33^{\mathrm{a}} \pm 6$ & $3^{\mathrm{ab}} \pm \mathbf{7}$
\end{tabular}

a,b Letras diferentes na mesma linha indicam diferenças significativas entre faixas etárias pelo teste de Kruskal-Wallis $(p<0,05)$.

cado alo de coloração acastanhada na membrana celular dos linfócitos (Fig.1).

Em relação ao fator idade, a porcentagem de linfócitos $T$ foi superior a de linfócitos $B$ em todas as faixas etárias. Observou-se aumento no percentual de linfócitos T e B, do Grupo G1+G5 para o Grupo G3, bem como nos demais grupos, porém em menor escala. Considerando a porcentagem de linfócitos B, o Grupo G1+G5 apresentou diferença significativa $(p<0,05)$ quando comparado aos Grupos G3 e G2+G6 (Quadro 1).

$\mathrm{Na}$ avaliação dos efeitos sexo e propriedades não foram observadas diferenças significativas entre as porcentagens de linfócitos $\mathrm{T}$ e $\mathrm{B}$.

Quadro 2. Valores médios (em número absoluto) e desvio padrão dos leucócitos, linfócitos totais, linfócitos $T$ e linfócitos $B$, em sangue periférico, submetidos à técnica de imunocitoquímica, de fêmeas bovinas da raça Curraleiro, conforme a faixa etária, expressos em $/ \mu \mathrm{L}$

\begin{tabular}{lcccc}
\hline \multirow{2}{*}{ Grupos } & $\mathrm{G} 3$ & $\mathrm{G} 1+\mathrm{G} 5$ & $\mathrm{G} 2+\mathrm{G} 6$ & $\mathrm{G} 7$ \\
\cline { 2 - 5 } & $\leq 1 \mathrm{ano}(\mathrm{n}=22)$ & $1-3 \operatorname{anos}(\mathrm{n}=19)$ & $3-9 \operatorname{anos}(\mathrm{n}=41)$ & $\geq 10 \operatorname{anos}(\mathrm{n}=14)$ \\
\hline Leucócitos $(/ \mu \mathrm{L})$ & $10.714^{\mathrm{a}} \pm 2.195$ & $9.989^{\mathrm{a}} \pm 3.109$ & $9.298^{\mathrm{a}} \pm 2.962$ & $10.021^{\mathrm{a}} \pm 2.650$ \\
Linfócitos totais $(/ \mu \mathrm{L})$ & $7.314^{\mathrm{a}} \pm 1.600$ & $6.453^{\mathrm{ab}} \pm 2.054$ & $5.444^{\mathrm{b}} \pm 1.625$ & $5.667^{\mathrm{ab}} \pm 1.314$ \\
Linfócitos $\mathrm{T}(/ \mu \mathrm{L})$ & $4.946^{\mathrm{a}} \pm 1.308$ & $4.022^{\mathrm{ab}} \pm 1.280$ & $3.443^{\mathrm{b}} \pm 998$ & $3.634^{\mathrm{ab}} \pm 917$ \\
Linfócitos $\mathrm{B}(/ \mu \mathrm{L})$ & $2.514^{\mathrm{a}} \pm 659$ & $1.737^{\mathrm{b}} \pm 542$ & $1.778^{\mathrm{b}} \pm 582$ & $1.950^{\mathrm{ab} \pm 710}$ \\
\hline
\end{tabular}

a,b Letras diferentes na mesma linha indicam diferenças significativas entre faixas etárias pelo teste de Kruskal-Wallis $(p<0,05)$. 
Foram mensuradas quatro variáveis leucocitárias em valores absolutos de células, incluindo leucócitos, linfócitos totais, linfócitos T e linfócitos B. No grupo formado em função da faixa etária, houve diferença significativa em quase todas as variáveis absolutas, com exceção dos leucócitos. Observou-se maior número de linfócitos totais até um ano de idade e, posteriormente, declínio com o avançar da idade (Quadro 2).

$\mathrm{Na}$ avaliação dos resultados das variáveis absolutas em função do sexo, observou-se que os valores, com exceção dos linfócitos $B$, apresentaram diferenças significativas $(p<0,05)$, demonstradas no Quadro 3. Quanto aos valores encontrados nas comparações das diferentes propriedades, não foi observada diferença significativa em nenhuma das variáveis relacionadas (Quadro 4).

Quadro 3. Valores médios (em número absoluto) e desvio padrão dos leucócitos, linfócitos totais, linfócitos T e

linfócitos $B$, em sangue periférico, submetidos à técnica de imunocitoquímica, de bovinos sadios da raça Curraleiro em função do sexo, expressos em / $\mu \mathrm{L}$

\begin{tabular}{ccccc}
\hline Sexo & $\begin{array}{c}\text { Leucócitos } \\
(\mu \mathrm{L})\end{array}$ & $\begin{array}{c}\text { Linfócitos totais } \\
(\mu \mathrm{L})\end{array}$ & $\begin{array}{c}\text { Linfócitos } \mathrm{T} \\
(\mu \mathrm{L})\end{array}$ & $\begin{array}{c}\text { Linfócitos B } \\
(\mu \mathrm{L})\end{array}$ \\
\hline $\begin{array}{c}\text { Fêmeas } \\
\text { G3+G5 }\end{array}$ & $10.848^{\mathrm{a}} \pm 2.757$ & $7.268^{\mathrm{a}} \pm 1.858$ & $4.794^{\mathrm{a}} \pm 1.330$ & $2.311^{\mathrm{a}} \pm 692$ \\
$(\mathrm{n}=31)$ & & & & \\
Machos & $12.715^{\mathrm{b}} \pm 2.946$ & $9.198^{\mathrm{b}} \pm 2.566$ & $6.031^{\mathrm{b}} \pm 1.946$ & $2.824^{\mathrm{a}} \pm 1.021$ \\
$\begin{array}{l}\text { G4+G8 } \\
(\mathrm{n}=20)\end{array}$ & & &
\end{tabular}

a,b Letras diferentes na mesma coluna indicam diferenças significativas entre sexo, pelo teste de Mann-Whitney $(p<0,05)$.

Quadro 4. Valores médios (em número absoluto) e desvio-padrão dos leucócitos, linfócitos totais, linfócitos $T$ e linfócitos $B$, em sangue periférico, submetidos à técnica de imunocitoquímica, de bovinos sadios da raça Curraleiro em função das propriedades, expressos em $/ \mu \mathrm{L}$

\begin{tabular}{ccccc}
\hline $\begin{array}{c}\text { Proprie- } \\
\text { dade }\end{array}$ & $\begin{array}{c}\text { Leucócitos } \\
(\mu \mathrm{L})\end{array}$ & $\begin{array}{c}\text { Linfócitos totais } \\
(\mu \mathrm{L})\end{array}$ & $\begin{array}{c}\text { Linfócitos } \mathrm{T} \\
(\mu \mathrm{L})\end{array}$ & $\begin{array}{c}\text { Linfócitos } \mathrm{B} \\
(\mu \mathrm{L})\end{array}$ \\
\hline $\begin{array}{c}\mathrm{AG} 1+\mathrm{G} 2 \\
(\mathrm{n}=25)\end{array}$ & $8.664^{\mathrm{a}} \pm 2.029$ & $5.608^{\mathrm{a}} \pm 1.590$ & $3.533^{\mathrm{a}} \pm 1.044$ & $1.790^{\mathrm{a}} \pm 592$ \\
$\begin{array}{c}\text { BG5+G6 } \\
(n=35)\end{array}$ & $10.126^{\mathrm{a}} \pm 3.436$ & $5.875^{\mathrm{a}} \pm 1.978$ & $3.692^{\mathrm{a}} \pm 1.177$ & $1.747^{\mathrm{a}} \pm 554$ \\
& & & &
\end{tabular}

$\overline{a, b}$ Letras diferentes na mesma coluna indicam diferenças significativas entre propriedades, pelo teste de Mann-Whitney $(p<0,05)$.

\section{DISCUSSÃO}

Os valores médios do percentual de linfócitos T e B circulantes, encontrados neste trabalho, foram 64 e 32 , respectivamente, caracterizando predomínio dos linfócitos $T$, o que também foi observado por Park et al. (1992), Bittar et al. (2004) e Pessa-Morikawa et al. (2004). Vale ressaltar que os dois últimos autores citados ainda classificaram a população de linfócitos $\mathrm{T}$, em citotóxicos, auxiliares e linfócitos Tgd, o que não foi propósito desta pesquisa. Apesar disso, os resultados obtidos abrem novos horizontes de estudo neste sentido, considerando bovinos da raça Curraleiro.
De outra parte, Park et al. (1992) encontraram percentual de 45-53 para linfócitos T e 16-21 para linfócitos B em bovinos Holstein-Friesian, demonstrando valores máximos inferiores dessas células quando comparados àqueles encontrados nos bovinos Curraleiros desta pesquisa.

Adicionalmente, Bittar et al. (2004) identificaram diferentes perfis fenotípicos de linfócitos T e B circulantes em bovinos de origem européia, considerando as raças Hereford, Pardo Suíça e Holandesa. Esses autores obtiveram um total de $65,8 \%, 56,9 \%$ e $43,1 \%$ de linfócitos T para essas raças, respectivamente, sendo que o percentual da raça Hereford foi semelhante ao observado nos Curraleiros. Quanto aos linfócitos B, foram encontrados um total de $14,9 \%$ nos animais Hereford e Pardos Suíços, e $18,58 \%$ nos Holandeses, que compreendem valores inferiores aos encontrados nos bovinos deste estudo. Tal dessemelhança nos valores totais de linfócitos $B$ pode ser explicada pelo fato dos autores terem utilizado o anticorpo anti-CD21 na imunofenotipagem da linhagem B, que não corresponde a um marcador pan- $B$, ou seja, não detecta linfócitos em todas as fases de maturação. Já o anticorpo LCTB16A utilizado nesta pesquisa reconhece linfócitos de blastos a citos.

Neste contexto, Bittar et al. (2004) sugeriram que o perfil fenotípico do sangue periférico de bovinos europeus pode influenciar no padrão da imunidade clínica apresentada pelos animais, relacionando o menor nível de linfócitos T (CD4 e CD8) em animais da raça Holandesa a sua susceptibilidade a infecções por Babesia sp., enquanto maiores níveis de linfócitos $T$ justificariam a maior resistência da raça Hereford às infecções parasitárias. Fundamentado nesse raciocínio, parece coerente que isso possa ser extrapolado aos animais da raça Curraleiro, visto que estes apresentaram alto nível de linfócitos T circulantes e são animais que sabidamente apresentam maior resistência às infecções hemoparasitárias. Além do alto nível de linfócitos $T$ circulantes, os autores ainda inferiram que a proporção de linfócitos $T$ e $B$ circulantes também pode estar envolvida na imunidade clínica, sendo que animais com maior proporção $\mathrm{T}: \mathrm{B}$ apresentam maior resistência às hemoparasitoses, o que ocorre com bovinos Curraleiros.

Ainda, resultados soroepidemiológicos, obtidos por Juliano (2006), acerca de babesiose (Babesia bovis e $B$. bigemina) e leptospirose (Leptospira interrogans), nos Curraleiros, demonstraram que apesar dos animais estarem expostos cronicamente a esses patógenos, não houve alteração hematológica e da bioquímica sérica que indicasse algum estado mórbido. Ao contrário, houve evidências de que esses bovinos apresentam imunidade contra tais agentes, sem manifestação clínica da doença, indicando resistência ou adaptação suficiente do hospedeiro.

Nos resultados referentes à faixa etária, observou-se maior número de linfócitos em animais de até um ano e, posteriormente, declínio com o avançar da idade. Este comportamento refletiu tanto na dinâmica do número absoluto como no percentual de linfócitos $T$ e $B$, apresen- 
tando o mesmo padrão de distribuição, visto que animais em crescimento apresentam índices linfocitários mais elevados que os adultos, pois nesses a atividade imunogênica é mais intensa (Morris \& Large 1993, Garcia-Navarro \& Pachaly 1994, Paula Neto 2004). Estes resultados também estão de acordo com os obtidos por Paula Neto (2004), em bovinos da raça Curraleiro, em que houve diferença significativa no número absoluto de linfócitos entre as faixas etárias. $\mathrm{O}$ mesmo foi observado por Birgel $\mathrm{Jr}$ et al. (2001) e Costa et al. (2000), em trabalhos realizados com fêmeas bovinas das raças Jersey e Nelore, respectivamente, onde o número de linfócitos aumentou de forma significativa e gradativa, do nascimento aos 12 meses de idade e diminuiu a partir da puberdade.

Ainda, Ayoub \& Yang (1996) verificaram que as contagens absolutas de linfócitos totais permaneceram elevadas e semelhantes até os seis meses de idade em todos os animais avaliados, sendo que o número de linfócitos $T$ declinou a partir do sétimo e oitavo meses de idade, o que também foi observado por Wilson et al. (1996), Kulberg et al. (2004) e Kampen et al. (2006). Porém, ainda no estudo de Ayoub \& Yang (1996), o número de linfócitos B aumentou gradativamente, contudo, as causas dessa linfocitose persistente não foram esclarecidas, pois todos os animais apresentavam-se clinicamente sadios.

De acordo com Jain (1993), a diminuição do número de linfócitos com a idade é atribuída ao declínio primário de linfócitos $T$, em razão da diminuição da função do timo. Já o número de linfócitos $B$ permanece relativamente estável, o que ocorreu neste estudo, pois houve discreta queda no número de linfócitos $B$, enquanto ocorreram quedas bruscas de linfócitos $T$ entre as faixas etárias.

Com relação às variáveis estudadas em função do sexo, observou-se diferença significativa nos valores absolutos entre machos e fêmeas, exceto quanto aos linfócitos B, sendo que os valores encontrados nos machos foram superiores em relação às fêmeas, em cerca de 2.000 células. Acerca disso, Paula Neto (2004) também verificou que os machos apresentam valores de leucócitos e linfócitos superiores aos das fêmeas, relatando que esta variável compreende um dos fatores de influência no leucograma de bovinos da raça Curraleiro. Do mesmo modo, PessaMorikawa et al. (2004) verificaram que as porcentagens de todas as sub-populações de linfócitos $T$ nos machos foram maiores que $80 \%$, sendo superiores às das fêmeas. Em contrapartida, Biondo et al. (1998) e Benesi et al. (2002) não observaram influência do fator sexo no eritrograma e/ ou leucograma de bovinos, com a ressalva de que esses autores trabalharam com animais da raça Nelore.

Neste estudo, compararam-se os perfis linfocitários, relativo e absoluto dos animais de duas propriedades diferentes, não sendo verificada diferença significativa entre os valores de linfócitos $T$ e $B$, apesar da ocorrência de infestação de carrapatos e mosca do chifre, ausência de suplementação mineral e escore corporal baixo dos animais da propriedade B. Possivelmente, a menor condição corporal observada nos animais desta propriedade tenha como causas determinantes o manejo nutricional e sanitário inadequados, o que, de acordo com os resultados, não interferiu na imunidade celular e humoral desses bovinos.

Neste âmbito, Morris \& Large (1993) referem que moléstias riquetsiais e desnutrição podem causar linfopenia, por desencadear aumento na liberação de glicocorticóides, o que interfere diretamente na produção de linfócitos. Apesar desta evidência, no presente trabalho não foi observada diferença significativa no número de células dos animais das diferentes propriedades ou sequer algum bovino com linfopenia. Este resultado pode ser sustentado pela rusticidade dos Curraleiros e por uma provável resistência natural desses às condições adversas e hostis a que foram submetidos, pois, conforme descrito por Carvalho \& Amorim (1989), Mariante \& Cavalcante (2000), Paula Neto (2004), Juliano (2006) e Barini (2007), a raça Curraleiro formou-se em regime de criação superextensiva, com mínimos cuidados sanitários e alimentares. Além disso, a raça adaptou-se ao calor e à seca, o que resultou, com o passar dos séculos, em animais extremamente rústicos, com características de boa adaptação ao meio e maior resistência a doenças e parasitas.

Não foi observada nenhuma alteração leucocitária nos bovinos Curraleiros da Propriedade B, que estavam submetidos a um estresse nutricional intenso. Já Cuenca et al. (2007), em pesquisa envolvendo bezerros e vacas acometidos por desnutrição provocada por intensa seca, constataram linfocitose em todos os bezerros e em $92 \%$ das vacas, concluindo ser uma resposta do organismo frente a um estresse nutricional. Por outro lado, estes autores descreveram que as vacas que não apresentaram alterações linfocitárias compreendiam animais mais velhos e possivelmente apresentavam maior adaptabilidade a condições desfavoráveis. Isto é, em parte, semeIhante ao observado nesta pesquisa, em que não se verificaram alterações leucocitárias nos animais das diferentes faixas etárias, provavelmente pela rusticidade da raça associada à alta adaptabilidade, especialmente dos animais mais velhos.

Também Meglia et al. (2005) realizaram um estudo comparando diferentes dietas e suas conseqüências junto ao perfil leucocitário de bovinos. Observaram que o número de leucócitos e linfócitos foi maior nos animais que receberam menores quantidades de energia, contrastando com os resultados obtidos no presente estudo, onde independente das condições alimentares, o perfil leucocitário manteve-se estável e dentro dos parâmetros de normalidade para a espécie. Da mesma forma Oliveira et al. (2005) não verificaram alterações leucocitárias alterando a dieta de bovinos.

A ausência de linfopenia e linfocitose nos animais da propriedade $\mathrm{B}$ pode estar relacionada à resistência adquirida ao longo dos séculos, ou seja, mesmo na presença de uma quantidade moderada de carrapatos e diferentes manejos nutricionais, o perfil linfocitário não foi alterado, talvez pela alta proporção de linfócitos T verificada, como também ocorreu com os bovinos Hereford do estudo de Bittar 
et al. (2004). Neste sentido, reitera-se a rusticidade da raça Curraleiro como fator preponderante de resistência a infecções, particularmente às hemoparasitárias.

\section{CONCLUSÕES}

As variáveis linfocitárias dos bovinos da raça Curraleiro sofreram significativas influências dos fatores idade e sexo, com diminuição das mesmas nos animais mais veIhos e maior proporção nos machos.

A diferença na qualidade de manejo não influenciou nenhum dos parâmetros avaliados.

Agradecimentos.- À Coordenação de Aperfeiçoamento de Pessoal de Ensino Superior (CAPES) e ao Programa de Pós-Graduação da Escola de Veterinária, Universidade Federal de Goiás (UFG), ao Ministério da Integração Nacional e ao Conselho Nacional de Desenvolvimento Científico e Tecnológico (CNPq).

\section{REFERÊNCIAS}

Allen D.M. 1992. Suckler Herds, p.922. In: Andrews A.H., Blowey R.W. Boyd H. \& Eddy R.G. (Eds), Bovine Medicine: Diseases and husbandry of cattle. Blackwell Science, Cambridge.

Ayoub I.A. \& Yang T.J. 1996. Age-dependent changes in peripheral blood lymphocyte subpopulations in cattle: A longitudinal study. Develop. Comp. Immunol. 20(5):353-363.

Barini A.C. 2007. Bioquímica sérica de bovinos (Bos taurus) sadios da raça Curraleiro de diferentes idades. Dissertação de Mestrado em Ciência Animal, Universidade Federal de Goiás, Goiânia. 90p.

Benesi F.J., Costa J.N., Birgel E.H., D‘Angelino J.L., Ayres M.C.C. \& Filho I.R.B. 2002. Leucograma padrão de bovinos da raça Nelore (Bos indicus). Influência de fatores sexuais. Vet. Notícias 8(1):59-66.

Biondo A.W., Lopes S.T.A., Kohayagawa A., Takahira R.K. \& Alencar N.X. 1998. Hemograma de bovinos (Bos indicus) sadios da raça nelore no primeiro mês de vida, criados no estado de São Paulo. Ciência Rural 28(2):251-256.

Bittar J.F.F., Ribeiro M.F.B., Marciano A.P.V., Salcedo J.H.P. \& MartinsFilho O.A. 2004. Perfil fenotípico de linfócitos periféricos de bovinos de raças européias. Arq. Bras. Med. Vet. Zootec. 56(1):107-110.

Birgel E.H. 1982. Hematologia clínica veterinária, p.2-34. In: Birgel E.H. \& Benesi F.J. (Eds), Patologia Clínica Veterinária. Sociedade Paulista de Medicina Veterinária, São Paulo.

Birgel Jr E.H., D’Angelino J.L., Benesi F.J. \& Birgel E.H. 2001. Valores de referência do leucograma de bovinos da raça Jersey criados no Estado de São Paulo. Braz. J. Vet. Res. Anim. Sci. 38(3):136-141.

Carvalho J.H. \& Amorim G.C. 1989. Preservação e avaliação do gado pé duro. Circ. Téc. 44, Embrapa, Teresina, Pl. 5p.

Coles E.H. 1986. Veterinary Clinical Pathology. 3rd ed. W.B. Saunders, Philadelphia. 566p.

Costa J.N., Benesi F.J., Birgel E.H., D’Angelino J.L., Ayres M.C.C. \& Barros Filho I.R. 2000. Fatores etários no leucograma de fêmeas zebuínas sadias da raça Nelore (Bos indicus). Ciência Rural 30(3):399403.

Cuenca E.M., Yero O.M., Freeman P., Porras O.M., Rosseaux J.D., Sánches W.R. \& Tamayo W.S. 2007. Reacción leucocitaria ante el estrés nutricional provocado por la sequía en bovino. Revta Electrón. Vet. 8(7):1695-7504.

Garcia-Navarro C.E.K. \& Pachaly J.R. 1994. Manual de Hematologia Veterinária. Varela, São Paulo, p.169.

Gibson J.P. 2002. Role of genetically determined resistance of livestock to disease in the developing world: Potential impacts and researchable issues, p.1-14. In: Perry B.D., Randolph T.F., McDermott K.R., Sones
K.R. \& Thornton P.K. (Eds), Investing in Animal Health Research to Alleviate Poverty. International Livestock Research Institute, Nairobi.

Gibson J.P. \& Bishop S.C. 2005. Use of molecular markers to enhance resistance of livestock to disease: A global approach. Rev. Sci. Technol. 24(1):343-353.

Hsu S.M., Raine L. \& Fanger H. 1981. Use of avidin-biotin-peroxidase complex $(A B C)$ in immunoperoxidase techniques: A comparison between $A B C$ and unlabeled (PAP) procedures. J. Histochem. Cytochem. 29(4):577-580.

Jain N.C. 1993. Essentials of Veterinary Hematology. Lea and Febiger, Pensylvania, p.989.

Juliano R.S. 2006. Aspectos sanitários e imunológicos de bovinos da raça curraleiro. Tese de Doutorado em Sanidade Animal, Universidade Federal de Goiás, Goiânia. 107p.

Kampen A.H., Olsen I., Tollersrud T., Storset A.K. \& Lund A. 2006. Lymphocyte subpopulations and neutrophil function in calves during the first 6 months of life. Vet. Immunol. Immunopathol. 13(1/2):5363.

Kimura K., Goff J.P., Kehrli Jr M.E. \& Harp J.A. 1999. Phenotype analysis of peripheral blood mononuclear cells in periparturient dairy cows. J. Dairy Sci. 82(2):315-319.

Knowles T.G., Edwards J.E., Bazeley K.J., Brown S.N., Butterworth A. \& Warriss P.D. 2000. Changes in the blood biochemical and hematological profile of neonatal calves with age. Vet. Rec. 174(21):593598.

Kulberg S., Boysen P. \& Storset A.K. 2004. Reference values for relative numbers of natural killer cells in cattle blood. Dev. Comp. Immunol. 28(9):941-948.

Mariante A.S. \& Cavalcante N. 2000. Animais do Descobrimento: Raças domésticas da história do Brasil. Embrapa Recursos Genéticos e Biotecnologia, Brasília. 227p.

Mariante A.S. \& Egito A.A. 2002. Animal genetic resources in Brazil: Result of five centuries of natural selection. Theriogenology 57:223235.

Meglia G.E., Johannisson A., Agenäs S., Holtenius K. \& Waller K.P. 2005. Effects of feeding intensity during the dry period on leukocyte and lymphocyte sub-populations, neutrophil function and health in periparturient dairy cows. Vet. J. 169(3):376-384.

Morris D.D. \& Large S.M. 1993. Alterações no leucograma, p.437-456. In: Smith B.P. (Ed.), Tratado de Medicina Interna de Grandes Animais. Vol.1. Manole, São Paulo.

Oliveira N.J.F., Melo M.M., Lago L.A. \& Nascimento E.F. 2005. Hemograma, bioquímica sérica e histologia da biópsia hepática de bovinos após administração de polpa cítrica. Arq. Bras. Med. Vet. Zootec. 57(3):418-422.

Park Y.H., Fox L.K., Hamilton M.J. \& Davis W.C. 1992. Bovine mononuclear leukocyte subpopulations in peripheral blood and mammary gland secretions during lactation. J. Dairy Sci. 75(5):998-1006.

Paula Neto J.B. 2004. Hemogramas de bovinos (Bos taurus) sadios da raça Curraleiro de diferentes idades, machos e fêmeas, gestantes e não gestantes. Dissertação de Mestrado em Sanidade Animal, Universidade Federal de Goiás, Goiânia. 65p.

Pessa-Morikawa T., Niku M. \& livanainen A. 2004. Persistent differences in the level of chimerism in B versus T cells of freemartin cattle. Dev. Comp. Immunol. 28(1):77-87.

Rangel P.N., Zucchi M.I. \& Ferreira M.E. 2004. Similaridade entre raças bovinas brasileiras. Pesq. Agropec. Bras. 39(1):97-100.

Sampaio I.B.M. 2007. Estatística aplicada à experimentação animal. Fundação de Ensino e Pesquisa em Medicina Veterinária e Zootecnia, Belo Horizonte, p.221.

Wilson R.A., Zolnai A., Rudas P. \& Frenyo L.V. 1996. T-Cell subsets in blood and lymphoid tissues obtained from fetal calves, maturing calves, and adult bovine. Vet. Immunol. Immunopathol. 53(1):49-60. 